Running Head: HIDDEN COSTS OF HIDING STIGMA

\title{
Hidden Costs of Hiding Stigma: Ironic Interpersonal Consequences of Concealing a Stigmatized Identity in Social Interactions
}

\author{
Anna-Kaisa Newheiser ${ }^{1}$ \\ Manuela Barreto $^{1,2}$ \\ ${ }^{1}$ University of Exeter, UK \\ ${ }^{2}$ Instituto Universitario de Lisboa (ISCTE-IUL), CIS, Lisbon, Portugal
}

\begin{abstract}
Author Note
Anna Newheiser is now at the University of Washington. The authors contributed equally to this article. Please address correspondence regarding this research to Dr. Anna Newheiser, Department of Psychology, University of Washington, Box 351525, Seattle, WA 98195, USA, or Prof. Manuela Barreto, School of Psychology, University of Exeter, Exeter EX4 4QG, UK. Email addresses: newhea@uw.edu and m.barreto@exeter.ac.uk.
\end{abstract}




\begin{abstract}
People who possess a concealable stigmatized identity (e.g., minority sexual orientation; history of mental illness) often hide this identity from others in order to avoid bias. Despite the possible benefits of this identity management strategy, we propose that instead of increasing acceptance, hiding a stigmatized identity can result in a lowered sense of belonging and even actual social rejection. Across four studies, we show that although individuals living with concealable stigmatized identities report a preference for hiding (vs. revealing) the identity during social interactions, hiding in fact reduces feelings of belonging — an effect that is mediated by felt inauthenticity and reduced general self-disclosure (i.e., disclosure of self-relevant information not limited to the stigmatized identity). Furthermore, the detrimental interpersonal effects of hiding (vs. revealing) a stigmatized identity are detected by external observers and nonstigmatized interaction partners. Implications for understanding the predicament of people living with stigmatized social identities are discussed.
\end{abstract}

Keywords: Concealable stigmatized identities; Identity management; Interpersonal interactions; Belonging; Authenticity 
Hidden Costs of Hiding Stigma: Ironic Interpersonal Consequences of Concealing a Stigmatized Identity in Social Interactions

People who are socially stigmatized possess an identity that is devalued by others (Crocker, Major, \& Steele, 1998). Stigmatized identities can be immediately visible to others (conspicuous; e.g., minority race/ethnicity or obesity) or invisible unless revealed (concealable; e.g., minority sexual orientation or a history of mental illness). Thus, an individual who possesses a concealable stigmatized identity is not immediately discredited but is "discreditable" (Goffman, 1963): Keeping the identity hidden may protect the individual from devaluation, but once the identity is revealed, the individual risks facing prejudice and discrimination. Perhaps unsurprisingly, the majority of existing work on concealable stigmatized identities has focused on the (anticipated) benefits of hiding one's identity and "passing" as a member of a nonstigmatized group (Goffman, 1963; Jones et al., 1984). However, we suggest that hiding a stigmatized identity has important costs. Specifically, we propose that instead of increasing social acceptance, hiding a stigmatized identity can enhance feelings of rejection and may impair intimacy and acceptance within social interactions. In the present research, we thus extended past work by examining the interpersonal ramifications of hiding a concealable stigmatized identity from interaction partners.

People living with stigmatized identities regularly face prejudice, stereotyping, and discrimination, biases that have a considerable negative impact on wellbeing and life outcomes (Crocker et al., 1998; Jones et al., 1984). Because it is possible to keep a concealable stigmatized identity hidden from others and thereby attempt to avoid stigmatization, it is often assumed that concealable stigmatized identities are less problematic than conspicuous ones (e.g., Jones et al., 1984). Similarly, passing, or hiding a concealable stigmatized identity in order to present the self 
as possessing a more valued social identity (Goffman, 1963; Katz, 1981), is typically viewed as a primary coping strategy among members of stigmatized groups. For instance, as noted by Goffman (1963), "because of the great rewards in being considered normal, almost all persons who are in a position to pass will do so on some occasion by intent" (p. 74). Indeed, researchers have recommended keeping a concealable stigmatized identity hidden unless concealment is causing considerable distress (Kelly \& McKillop, 1996). Thus, the majority of previous research has focused on the desire to secure acceptance as a central reason why individuals hide a stigmatized identity from others. Accordingly, previous research implies that concealing a devalued identity is likely to have positive interpersonal consequences. In fact, a considerable amount of prior work has documented that individuals living with concealable stigmatized identities themselves believe that they will benefit from keeping their devalued identities hidden. For example, people anticipate that hiding their stigmatized identities will allow them to make a more positive impression on others (Barreto, Ellemers, \& Banal, 2006).

Despite these anticipated benefits of concealing a stigmatized identity that are suggested by past research, we propose that these expectations may not actually be borne out, and that, in contrast, concealment may be detrimental to social interactions. Supporting our reasoning, some previous work has found that hiding a stigmatized identity can involve important costs, including negative affect, anxiety, and depression (Frable, Platt, \& Hoey, 1998) and an elevated risk of physical (Cole, Kemeny, Taylor, \& Visscher, 1996) and mental illness (Meyer, 2003). Additionally, experimental research has revealed that hiding a devalued identity during social interactions reduces cognitive resources (Smart \& Wegner, 1999) and increases negative selfdirected affect (Barreto et al., 2006). Accordingly, as suggested by Meyer (2003), "concealing one's stigma is often used as a coping strategy, aimed at avoiding negative consequences of 
stigma, but it is a coping strategy that can backfire and become stressful" (p. 681) and may therefore result instead in reduced wellbeing.

Although prior research has examined cognitive (Smart \& Wegner, 1999) and emotional (Barreto et al., 2006) costs of hiding a stigmatized identity, the interpersonal costs of this identity management strategy have as yet to be the focus of systematic empirical examination. In the present research, our aim was to add to existing knowledge regarding the consequences of "passing" by experimentally examining how hiding (vs. revealing) a stigmatized identity affects belonging and acceptance in social interactions. Specifically, although people may believe that hiding a stigmatized identity will help them secure social inclusion, we propose that it can ironically increase feelings of exclusion, and even actual exclusion by others. Whereas researchers have acknowledged the importance of issues of acceptance for individuals living with stigmatized identities (e.g., Chaudoir \& Fisher, 2010; Goffman, 1963; Rodriguez \& Kelly, 2006), existing empirical work has not directly examined belonging and acceptance in interpersonal interactions (as noted by Chaudoir \& Fisher, 2010). Accordingly, we extended prior work by examining the effects of hiding (vs. revealing) a devalued identity during interpersonal interactions, including face-to-face interactions in the lab, and by investigating the complementary perspectives of stigmatized individuals, external observers, and non-stigmatized interaction partners.

In addition, we sought to understand the psychological processes that may help explain the hypothesized interpersonal consequences of hiding (vs. revealing) a stigmatized identity. Specifically, we propose that hiding a stigmatized identity makes an individual vulnerable to lack of belonging and rejection because hiding one's true identity curbs both general self-disclosure and feelings of authenticity. First, one could plausibly expect that disclosure of self-relevant 
information to an interaction partner might be increased when an individual is attempting to conceal one aspect of the self (i.e., a devalued identity); for instance, one might seek to increase disclosure of other information about the self in order to direct the conversation to "safer" topics. However, because hiding a stigmatized identity is associated with the fear of being "found out" (Ragins, Singh, \& Cornwell, 2007) and with careful monitoring of one's behavior to avoid exposure (Frable, Blackstone, \& Scherbaum, 1990), we propose that individuals who hide (vs. reveal) a stigmatized identity are likely to self-disclose to a lesser extent during social interactions. That is, hiding a stigmatized identity (e.g., minority sexual orientation) requires one to limit the amount of personal information (e.g., the name of one's romantic partner) to which others have access, including personal information not associated with the stigma, in order to ensure that the identity is not unintentionally revealed. Self-disclosure is critical for developing intimacy and belonging in both interpersonal and intergroup relationships (Collins \& Miller, 1994; Turner, Hewstone, \& Voci, 2007), and relative lack of disclosure may result in awkward and distant social interactions (Herek, 1996). Accordingly, we hypothesized that hiding (vs. revealing) a stigmatized identity results in a reduced sense of belonging and an increased likelihood of social rejection in part because it generally inhibits disclosure of self-relevant information to interaction partners.

Second, as noted by Barreto and Ellemers (2003), "passing” involves both presenting oneself as a member of a non-stigmatized group and covering one's true, socially devalued identity. Whereas positive self-presentation may be expected to incur benefits (e.g., protection from bias; Quinn, Kahng, \& Crocker, 2004), the act of deceit implicated in denying one's true identity has negative psychological consequences (Barreto et al., 2006). Specifically, hiding a concealable stigmatized identity may restrict the degree to which one can experience a sense of 
authenticity, of being true to oneself (Goffman, 1963; Leary, 1999; Major \& Gramzow, 1999; Wood, Linley, Maltby, Baliousis, \& Joseph, 2008). The fact that hiding compromises one's selfimage as moral (Barreto et al., 2006), coupled with the crucial role morality plays in selfdefinition (Schwartz, 1992; Van Lange \& Sedikides, 1998), leads us to suggest that hiding (vs. revealing) a stigmatized identity is likely to result in feelings of inauthenticity. Supporting this reasoning, authenticity involves living in accordance with one's values and beliefs (i.e., significant facets of one's true identity) rather than conforming to others' expectations (Wood et al., 2008). Accordingly, hiding a devalued identity is likely to be associated with experiences of inauthenticity (Lenton, Bruder, Slabu, \& Sedikides, 2013). Thus, we hypothesized that hiding (vs. revealing) a stigmatized identity results in a reduced sense of belonging in social interactions in part because it is inconsistent with being true to oneself.

In summary, in the present work we examined the interpersonal consequences of hiding (vs. revealing) a stigmatized identity. Individuals who are motivated to avoid rejection are less likely to reveal their concealable stigmatized identities (Garcia \& Crocker, 2008). Ironically, however, the very act of hiding one's stigmatized identity from an interaction partner is hypothesized to increase feelings of rejection. We tested these hypothesized processes across four studies. First, in Studies 1a and 1b, we sought to demonstrate that individuals living with a variety of concealable stigmatized identities (i.e., LGBT identity; a history of mental illness; a history of physical illness not directly visible to others; and poverty) would report that they would choose to hide (rather than reveal) their identity during social interactions, and believe that revealing the identity would have negative interpersonal consequences. The aim of Studies 2 and 3 was to demonstrate that these anticipated interpersonal consequences of revealing (vs. hiding) a devalued identity are not borne out during actual face-to-face social interactions. In 
particular, in Study 2 we sought to show that feelings of inauthenticity and reduced general selfdisclosure mediate the effects of hiding (vs. revealing) a contextually devalued identity on lack of belonging and social rejection, and that the consequences of hiding (vs. revealing) can be detected both by the stigmatized individuals themselves and by external observers. In Study 3 , we examined social interactions between stigmatized and non-stigmatized participants (specifically, participants with and without a history of mental illness), seeking to demonstrate that non-stigmatized participants experience reduced levels of intimacy during the interaction when their partner hides (vs. reveals) their history of mental illness. Focusing on a variety of different research paradigms, stigmatized identities, and participant samples, these four studies converge to demonstrate that although individuals living with concealable stigmatized identities expect to benefit from hiding their devalued identities from interaction partners (Studies 1a and 1b), this expectation may be too optimistic, and, ironically, the act of hiding has a negative impact on social interactions (Studies 2 and 3).

\section{Studies $1 \mathrm{a}$ and $1 \mathrm{~b}$}

In Studies 1a and 1b, our aim was to provide evidence that individuals living with concealable stigmatized identities believe that they benefit interpersonally from not revealing their identities, and when given the choice, would opt to hide (rather than reveal) their identities. Accordingly, in Studies 1a and 1b, participants who reported possessing a concealable stigmatized identity were asked to imagine a social interaction taking place within a workplace context, and were asked whether they would choose to hide or reveal their identities during the interaction (Study 1a; a correlational design), or were asked to reflect on the consequences of hiding versus revealing the identity (Study $1 \mathrm{~b}$; an experimental design).

\section{Study 1a Method}


Study 1a Participants. Forty-nine participants ( 22 women, 25 men, two participants did not report their gender; mean age $=30.26, S D=11.26$, range: $18-60 ; 76 \%$ White/Caucasian) were recruited via Amazon's Mechanical Turk (see Buhrmester, Kwang, \& Gosling, 2011) in return for US\$0.50.

Study 1a Procedure and Measures. Participants were told the study examined "people's experiences at the workplace, as well as the role that different identities may play in those experiences." Participants were first asked to report whether they viewed themselves as possessing a particular identity; we used this task to recruit participants who possessed one of four concealable stigmatized identities (LGBT identity, history of mental illness, history of physical illness not directly visible to others, or poverty; see Frable et al., 1998, for a study investigating a similar set of concealable stigmatized identities). Specifically, participants indicated which of the following statements best described them: "I am gay, lesbian, bisexual, or transgender"; "I have experienced or am currently experiencing mental health issues that have significantly impacted my life (e.g., depression, eating disorder)"; "I have experienced or am currently experiencing physical health issues that are not immediately visible to others but have significantly impacted my life (e.g., epilepsy)"; "I have experienced or am currently experiencing poverty or very low socioeconomic status"; and "None of these statements describes me." The study terminated automatically if participants selected the final option. Participants who possessed more than one of these identities were instructed to "select the one that is most central or important in your life." Five participants reported possessing an LGBT identity; 17 participants reported having a history of mental health issues; six participants reported having a history of "invisible" physical health issues; and 21 participants reported having experience with poverty. Participants then reported their current occupation, how long 
they had had their current job $(M=2.97$ years, $S D=4.06)$, and how many years of work experience they had in total $(M=12.38$ years, $S D=12.18)$.

Next, participants were told that the study examined "the workplace experiences of people who have identities that may be devalued or perceived negatively by others" and that we were specifically interested in the identity they had selected in the first task. Participants were asked to read a description of a situation they might experience at work and imagine how they would feel or react in the situation. Participants read the following scenario (the text in square brackets varied depending on participants' self-reported identity): "You have recently started working at a new workplace. One day during the lunch break, one of your coworkers talks about her cousin, who [is gay] [is in treatment for severe depression] [has epilepsy] [lives below the poverty line], going into some detail about her cousin's life. Your coworkers then begin to talk more generally about people who [are gay, lesbian, bisexual, or transgender] [have mental health issues] [have epilepsy or other "invisible" physical health issues] [are poor]. Your coworkers do not know that you [are gay, lesbian, bisexual, or transgender] [have suffered from mental health issues] [suffer from an "invisible" physical health issue] [have personal experience with poverty]." Importantly, the scenario was evaluatively neutral and did not imply that the coworkers in this situation necessarily devalued participants' identity or that participants would necessarily face any particular consequence based on this social interaction.

Participants then responded to the following three items: "If you were to find yourself in this situation, having this conversation with your coworkers, would you choose to reveal this fact about yourself or would you instead choose to conceal it?" (1=would definitely reveal to 7=would definitely conceal); "To what extent do you expect that revealing your identity during this kind of a conversation with your coworkers would affect your relationships at work?"; and 
"To what extent do you expect that concealing your identity during this kind of a conversation with your coworkers would affect your relationships at work?" (response scale for the latter two items: $1=$ would have a strong negative effect to $4=$ would make no difference to $7=$ would have $a$ strong positive effect).

Next, participants responded to five additional items about their identities ( $1=$ strongly disagree to $7=$ strongly agree . Two items assessed the extent to which participants were open about their identities ("I am usually open about this identity; most people know about it" and "I am open about this identity at work; most of my colleagues know about it"; $r(45)=.85, p<.001$; adapted from Waldo, 1999). Two items assessed ingroup identification ("This identity is important to me" and "I feel a connection to other people who also have this identity"; $r(45)=.46$, $p=.001)$. Participants scored around the scale midpoint on openness about their identities $(M=3.53, S D=2.05)$ and ingroup identification $(M=4.38, S D=1.48)$. Thus, participants were not completely open about their identities (ensuring that questions regarding concealment were appropriate within this sample), and participants rated the identities as relatively important (ensuring that any obtained effects would be related to meaningful aspects of participants' lives). One item assessed perceptions of bias against one's ingroup (“Other people often have negative attitudes toward people who have this identity"). As anticipated, participants perceived bias against their identities $(M=5.38, S D=1.47)$; the mean was significantly above the scale midpoint, one-sample $t(44)=6.30, p<.001$. This result confirmed that the concealable identities included in this study can be appropriately characterized as stigmatized. Finally, participants provided basic demographic information and were debriefed.

\section{Study 1a Results}


To examine the hypothesis that participants would be inclined to choose to conceal (vs. reveal) their identities during social interactions with colleagues at work and would perceive revealing their identities as a negative experience, we conducted one-sample $t$-tests. As predicted, participants were more likely to report that they would choose to conceal, rather than reveal, their identities $(M=5.00, S D=1.98)$; the mean was significantly above the scale midpoint, $t(48)=3.54, p=.001$. That is, $67 \%(n=33$ out of 49$)$ of participants selected a response above the scale midpoint, indicating a preference for concealing over revealing a stigmatized identity among a clear majority of participants. Indeed, the modal response was " 7 ," labeled "would definitely conceal" (selected by 16 participants).

As also predicted, participants reported believing that revealing their identities would have a negative effect on their relationships at work $(M=3.37, S D=1.50)$; the mean was significantly below the scale midpoint (which was labeled "would make no difference"), $t(48)=-$ 2.96, $p=.005$. In contrast, participants reported believing that concealing their identities would have no effect on their relationships at work $(M=3.98, S D=1.18)$; the mean was not different from the scale midpoint (which was labeled "would make no difference"), $t(48)=-0.12, p=.904{ }^{1}$

Finally, supplementary correlational analyses indicated that participants who were more open about their identities were less likely to report a preference for hiding (vs. revealing), $r(45)=-.65, p<.001$, and less likely to believe that revealing would have a negative impact on their interpersonal relationships, $r(45)=.66, p<.001$. Openness about the identity was not significantly associated with beliefs regarding the interpersonal impact of hiding, $r(45)=-.22$, $p=.137$. In addition, participants who perceived more bias against their identities were more likely to report a preference for hiding (vs. revealing), $r(43)=.48, p=.001$, and more likely to believe that revealing would have a negative impact on their interpersonal relationships, $r(43)=-$ 
$.51, p<.001$. Perceived bias was not associated with beliefs regarding the interpersonal impact of hiding, $r(43)=.01, p=.950$. Ingroup identification was not significantly associated with preference for hiding (vs. revealing) or with beliefs regarding the interpersonal impact of hiding or revealing, $-.15<r<.08, p \mathrm{~s} \geq .308$.

\section{Study 1a Discussion}

As anticipated, Study 1a demonstrated that when asked to choose between revealing and concealing their concealable stigmatized identities during a social interaction at work, participants indicated that they would choose to keep the identity hidden. Participants further reported a belief that revealing the identity would negatively impact their relationships at work, suggesting that individuals living with concealable stigmatized identities are motivated to keep their identities concealed from others due to the perceived negative consequences of revealing the identity. Finally, the finding that participants reported that concealing their identities would not affect their relationships at work suggests that they may expect that what others do not know will not have social or interpersonal consequences. Taken together, these results suggest that participants expect both that revealing a stigmatized identity is clearly detrimental to social interactions and that hiding the identity is a socially "neutral" act. In Studies 2 and 3, we test the hypothesis that neither expectation will be borne out during actual social interactions-with revealing a devalued identity failing to result in interpersonal ramifications and hiding the identity in fact increasing such ramifications.

Study $1 \mathrm{~b}$ employed an experimental design in order to provide further evidence that, when given the choice, participants would prefer to conceal (rather than reveal) a stigmatized identity. Specifically, in Study 1b, participants first imagined a situation in which they either concealed or revealed a stigmatized identity in the same workplace scenario as in Study 1a. Next, 
we asked participants to imagine a counterfactual situation, such that having first imagined revealing their identity, they subsequently imagined concealing it (or vice versa). We predicted that participants would report that concealing (vs. revealing) the identity would be a more positive interpersonal experience.

\section{Study 1b Method}

Study 1b Participants. One hundred and five participants (45 women, 60 men; mean age $=30.90, S D=10.82$, range: $18-73 ; 71 \%$ White/Caucasian) were recruited via Amazon's MTurk in return for US $\$ 0.50$.

Study 1b Procedure, Design, and Measures. The procedure was modeled closely after Study 1a. Participants were again told the study examined "people's experiences at the workplace, as well as the role that different identities may play in those experiences" and began the study by indicating whether they viewed themselves as possessing one of four concealable stigmatized identities. Twelve participants reported possessing an LGBT identity; 38 participants reported having a history of mental health issues; 13 participants reported having a history of "invisible" physical health issues; and 42 participants reported having experience with poverty. Participants next reported their current occupation, how long they had had their current job ( $M=3.95$ years, $S D=4.34)$, and how many years of work experience they had in total $(M=11.41$ years, $S D=9.87)$.

Participants were then randomly assigned to the Hide $(N=51)$ or Reveal $(N=54)$ conditions. As in Study 1a, participants were told the study examined "the workplace experiences of people who have identities that may be devalued or perceived negatively by others" and read the same base scenario as in Study 1a. In the Hide condition, the base scenario ended as follows: "Now imagine that you do not reveal to your coworkers that you have personal 
experience with this identity. You continue the conversation with your coworkers, concealing this fact about yourself and not mentioning your personal experiences related to this identity." By contrast, in the Reveal condition the base scenario ended as follows: "Now imagine that you reveal to your coworkers that you have personal experience with this identity. You continue the conversation with your coworkers, mentioning this fact about yourself and telling your coworkers about your personal experiences related to this identity." Participants then responded to 14 items assessing anticipated positivity of the interaction (e.g., "I would expect this interaction with my coworkers to be natural and relaxed"; "I would expect to enjoy this interaction with my coworkers"; "I would expect this interaction with my coworkers to go poorly," reverse-scored; "I would prefer not to have an interaction like this with my coworkers," reverse-scored; $1=$ strongly disagree to $7=$ strongly agree $; \alpha=.92)$.

Next, we asked participants to imagine a counterfactual situation, as follows (the text in square brackets was presented in the Reveal condition): "Now, we would like you to imagine the same situation, with the exception that you revealed [concealed] your identity to [from] your coworkers during the conversation, instead of concealing [revealing] it." Participants then responded to the same 14 items regarding the anticipated positivity of this counterfactual social interaction $(\alpha=.94)$.

Participants in both conditions were next asked to directly contrast the experience of revealing and concealing their identities on the following three items: "All things being otherwise equal, would you say the conversation with your coworkers would go more smoothly if you revealed or concealed your identity?" (1=would go much more smoothly if I revealed my identity to $4=$ this would not make any difference to how smoothly the conversation went to 7=would go much more smoothly if I concealed my identity); "All things being otherwise equal, 
would you say the conversation with your coworkers would be more comfortable if you revealed or concealed your identity?" ( $1=$ would be much more comfortable if I revealed my identity to 4=this would not make any difference to how comfortable the conversation was to $7=$ would be much more comfortable if I concealed my identity); and "All things being otherwise equal, would you reveal or conceal your identity in this situation?" (1=would definitely reveal to $7=$ would definitely conceal). Responses to these items were averaged into a single index of relative preference for concealment $(\alpha=.89)$.

Openness about one's identity $(r(103)=.83, p<.001 ; M=3.53, S D=1.79)$, ingroup identification $(r(103)=.42, p<.001 ; M=4.23, S D=1.46)$, and perceived bias $(M=4.84, S D=1.70)$ were assessed as in Study 1a. As in Study 1a, participants perceived bias against their identities (i.e., the mean was significantly above the scale midpoint, one-sample $t(104)=5.05, p<.001$ ). Thus, as in Study 1a, these results confirmed that questions related to concealment were appropriate within this sample (because participants were not fully open about their identities), that participants rated the identities as relatively important, and that the identities could be appropriately characterized as stigmatized. Participants finally provided basic demographic information and were debriefed.

\section{Study 1b Results}

Anticipated Positivity of the Interaction. We conducted a 2 (Condition: Hide vs. Reveal $) \times 2$ (Scenario: Initial vs. Counterfactual) mixed-model analysis of variance (ANOVA), with repeated measures on the second factor, on ratings of how well participants anticipated the interaction with their coworkers would go. This analysis revealed a main effect of Condition, $F(1,103)=23.60, p<.001, \eta_{p}^{2}=.19$, and a main effect of Scenario, $F(1,103)=7.91, p=.006$, $\eta_{p}^{2}=.07$, qualified by the expected interaction, $F(1,103)=6.87, p=.010, \eta_{p}^{2}=.06$. Analyses of 
simple effects (following the recommendations of Howell, 2002) revealed that participants in the Reveal condition rated the counterfactual scenario (in which they imagined concealing their identities; $M=4.24, S D=0.88$ ) as a more positive interpersonal experience than the initial scenario (in which they imagined revealing their identities; $M=3.71, S D=1.01$ ), $F(1,53)=11.02, p=.002$, $\eta_{p}^{2}=.17$. Participants in the Hide condition rated the initial $(M=3.11, S D=1.07)$ and counterfactual $(M=3.13, S D=1.15)$ scenarios equivalently, $F<1 .^{2}$ These effects did not change when we adjusted for openness about the identity, ingroup identification, and perceived bias against the identity in an analysis of covariance (ANCOVA). Openness about the identity, $F(1$, $100)=28.10, p<.001$, and perceived bias, $F(1,100)=14.34, p<.001$, were significant covariates (with openness predicting greater, and perceived bias predicting lesser, anticipated positivity in both the initial and counterfactual scenario), whereas ingroup identification was not a significant covariate, $F(1,100)=2.24, p=.138$.

Preference for Concealment. An independent-samples $t$-test revealed no effect of condition on preference for concealing, relative to revealing, one's identity, $t(103)=1.05, p=.294$. All participants expressed a preference for concealing over revealing (overall $M=4.98, S D=1.56$; significantly above the scale midpoint, one-sample $t(104)=6.47, p<.001)$. This pattern held independently within the two conditions (Hide condition: $M=5.15, S D=1.54$, significantly above the scale midpoint, one-sample $t(50)=5.33, p<.001$; Reveal condition: $M=4.83, S D=1.57$, significantly above the scale midpoint, one-sample $t(53)=3.87, p<.001) .{ }^{3}$ This pattern also held when we adjusted for openness about the identity, ingroup identification, and perceived bias against the identity in an ANCOVA. Supplementary correlational analyses collapsing across conditions indicated that, as in Study 1a, participants who were more open about their identities were less likely to report a preference for concealing (vs. revealing), $r(103)=-.56, p<.001$. Also 
as in Study 1a, participants who perceived more bias against their identities were more likely to report a preference for concealing (vs. revealing), $r(103)=.25, p=.009$. Ingroup identification was not associated with preference for hiding (vs. revealing), $r(103)=.00, p=.980$.

\section{Study 1b Discussion}

Study $1 b$ conceptually replicated the pattern observed in Study 1a: All participants, regardless of experimental condition, reported a preference for hiding (relative to revealing) their stigmatized identities. Furthermore, participants who had initially imagined revealing their identities subsequently rated the act of hiding as a more positive social and interpersonal experience. Importantly, although we noted to participants that we were interested in identities that may be generally perceived as devalued (though no such devaluation was mentioned in the context of the concrete situation in which participants were asked to imagine themselves), statistically controlling for perceived bias against one's identity did not change the pattern of results. We therefore conclude that individuals living with stigmatized identities believe that concealment is an interpersonally beneficial coping strategy.

We note that participants who had first imagined hiding their identities unexpectedly rated the experiences of hiding and revealing as equivalent. This unexpected null effect, as well as the generally lower mean scores on the measure of anticipated positivity of the interaction in the Hide condition, may reflect the possibility that participants in this condition may have imagined a workplace in which social interactions are generally less positive and intimate (though note that the scenario was intentionally neutral and did not imply any negativity toward participants' identity). That is, perhaps this condition brought to mind a workplace at which people rarely share personal information (not confined to the devalued identity) with coworkers; social interactions at such a workplace might generally speaking be relatively less positive, 
which may explain the lack of difference between the scenarios involving hiding and revealing a stigmatized identity. Most centrally, however, and as predicted, in no case did participants within a specific condition rate revealing a devalued identity as an interpersonally more positive experience than hiding the identity.

To summarize, participants in Studies 1a and 1b expected that they would benefit from hiding their devalued identities during a social interaction, and reported a highly consistent preference for keeping the identity hidden. In Studies 2 and 3, we examined how which these anticipated positive interpersonal consequences of concealment are not borne out.

\section{Study 2}

In Study 2 our aim was to demonstrate, first, that hiding a stigmatized identity from an interaction partner has negative social consequences, and second, that this effect arises in part because hiding one's identity limits one's sense of authenticity and the degree to which one generally discloses information about oneself. Thus, in Study 2 we randomly assigned participants to either hide or reveal a devalued identity during a face-to-face dyadic interaction. Unlike Studies 1a and 1b, which focused on culturally stigmatized identities, in Study 2 we examined a concealable identity that was important to participants' self-image and is typically valued, but was portrayed as devalued in the context of the study. Specifically, we focused on student participants' study major identity (for a similar procedure, see Barreto et al., 2006). Participants were told they would interact with another student who had (allegedly) explicitly expressed that they devalued participants' study major, and were randomly assigned to hide or reveal their study major identity during the interaction. We measured the extent to which participants felt authenticity and belonging in anticipation of the interaction. We hypothesized that expecting to hide (vs. reveal) a contextually devalued identity would result in lack of 
belonging, an effect that would be explained by concerns about authenticity. In addition, to assess the hypothesized processes during the interaction, we videotaped the interactions for subsequent coding by external observers (who were blind to study design and hypotheses). We hypothesized that participants who hid (vs. revealed) their identity would be perceived as disclosing less information about themselves (on a general level, that is, not limited to information about the devalued identity), and that these participants' interactions would consequently be perceived as less positive (representing actual lack of belonging). Importantly, given that the external observers were blind to study design and hypotheses, they were unaware of the fact that participants possessed a devalued identity.

\section{Method}

Participants. Fifty-seven Dutch university students participated in return for course credit or $€ 6$. One participant in the Hide condition opted not to hide her identity, yielding a final sample size of 56 (39 women, 17 men; mean age $=20.23, S D=2.95$ ).

Design, Procedure, and Measures. The study complied with the standards for ethical psychological research endorsed at Leiden University, where the data were collected. Participants first read and signed an informed consent form and then completed a series of measures (presented on a computer) individually in separate cubicles. Specifically, participants reported their age, gender, and study major, and responded to three items assessing identification with their study major (e.g., "I see myself as a [study major] student"; 1=completely disagree to 7=completely agree $; \alpha=.75)$. Participants next read instructions according to which students from different departments were completing the study simultaneously, and each would be paired with another student for a face-to-face interaction. Participants were further told that a computer would randomly assign one student in each pair to an "interviewer" role and one to an 
"interviewee" role. In reality, all participants were assigned to be interviewees; the interviewers were confederates.

In an adaptation of the procedure employed by Barreto et al. (2006), participants were next told that interviewers had been asked to state with whom they preferred to interact, based on interviewees' gender, age, and study major. Participants then received bogus information about their interviewer, who was always presented as a 22-year-old law student of the same gender as the participant. The interviewer, however, allegedly preferred to interact with a medical student (of the participant's gender and approximate age). Specifically, based on responses to three questions (e.g., "With a student of which study major would you find the interaction most interesting?"), the interviewer had allegedly ranked medicine as the most preferred and the participant's own study major as the second-to-least preferred. None of the participants was a medical student. This procedure thus served to create the impression that participants' study major was fairly strongly devalued by their interaction partner, thereby contextually stigmatizing this identity.

In order to introduce the experimental manipulation of hiding (vs. revealing) a stigmatized identity, participants were next told that there were not enough medical students present and it would therefore not be possible to follow all of the interviewer's preferences. At this point, participants in the Hide condition $(N=27)$ read instructions suggesting that they indicate to the interviewer that they were medical students, ${ }^{4}$ whereas participants in the Reveal condition $(N=29)$ read instructions suggesting that they indicate their real study major to the interviewer. All participants were asked to press an "OK" button to express their active agreement with this suggestion. This procedure gave participants an initial choice to hide or reveal their identity (i.e., to follow the instructions), while guaranteeing random assignment to 
conditions. As reported above, one participant (in the Hide condition) chose to end participation at this stage. Information about participants' age, gender, and study major was then allegedly sent to the interviewer. A manipulation check confirmed that all participants indicated the correct study major (i.e., their actual major in the Reveal condition and medicine in the Hide condition).

Participants next completed the dependent measures $(1=$ completely disagree to 7=completely agree). Three items assessed concerns about authenticity: "At this moment, I worry that during the interaction I'll not be myself"; "At this moment, I worry that during the interaction I'll not be honest with myself"; and "At this moment, I worry that during the interaction I'll give an incomplete picture of myself" $(\alpha=.88)$. Six items assessed felt belonging (e.g., "At this moment, I feel socially wanted"; "At this moment, I feel accepted"; $\alpha=.92$ ).

Next, the experimenter led the participant and the interviewer (i.e., the confederate) to a room equipped with a video camera and the interaction took place. The confederate, who was blind to study design and hypotheses, conducted the interview based on a 14-question script. The first several questions did not refer to the stigmatized identity (e.g., "Is this the first time you are participating in a psychology experiment?"). After the sixth question, the confederate said, "I saw you're studying medicine" (in the Hide condition) or "I saw you're studying [actual study major]" (in the Reveal condition), and the rest of the interview focused on participants' study major, ensuring that participants either actively hid or revealed their identity.

Finally, the videotaped interactions were rated $(1=$ not at all to $7=$ very $m u c h)$ by two external observers (blind to study design and hypotheses) whose gender was matched with that of the participant and confederate. ${ }^{5}$ Five items assessed participants' general level of disclosure: "To what extent do you feel that you came to know the participant?"; "How extensive was the participant in his/her answers?"; "How much do you think the participant revealed about 
himself/herself?"; "How much emotion did the participant express during the interaction?"; and "How prepared to respond was the participant during the interaction?" (intraclass correlation=.69). Two items indexed evaluation of the interaction: "Overall, this interaction seemed pleasant" and "Overall, this interaction seemed natural and relaxed" (intraclass correlation=.58). Three items indexed evaluation of the participant: "To what extent did you find the participant kind?"; "To what extent would you like to meet the participant?"; and "How intelligent did the participant seem?" (intraclass correlation=.70). External observers also measured the total duration (in seconds) of each interaction (intraclass correlation=.98), participant talk time (intraclass correlation=.98), and confederate talk time (intraclass correlation $=.54){ }^{6}$

\section{Results}

Participants' Self-ratings. Participants' identification with their study major, measured before the manipulation, was high (Hide condition: $M=5.28, S D=0.87$; Reveal condition: $M=5.41, S D=1.10$ ) and did not differ between conditions, $t(54)=0.49, p=.629$. Accordingly, participants in both conditions were in a position to be negatively impacted by their interaction partner's (alleged) devaluation of their identity.

We first assessed the effect of anticipating hiding (vs. revealing) a contextually devalued identity on concerns about authenticity and feelings of belonging. As predicted, participants reported greater concerns about authenticity in the Hide condition $(M=4.28, S D=1.59)$ than in the Reveal condition $(M=2.39, S D=1.12), t(54)=5.19, p<.001, d=1.41$. Also as predicted, participants reported lower belonging in the Hide condition $(M=4.02, S D=0.97)$ than in the Reveal condition $(M=4.72, S D=1.08), t(54)=-2.54, p=.014, d=0.69$. Thus, expecting to enter an interaction in which one would hide (vs. reveal) an identity that was devalued by one's interaction partner 
exacerbated concerns about being able to be true to oneself and resulted in a lower sense of belonging.

We next examined the prediction that concerns about authenticity would help explain the effect of hiding (vs. revealing) a devalued identity on feelings of belonging. When experimental condition and authenticity concerns simultaneously predicted felt belonging, authenticity concerns were a significant predictor, $p=.009$, whereas the effect of condition was nonsignificant, $p=.536$, consistent with mediation (see Figure 1). Bootstrapping (with 5000 resamples; see Hayes, 2013) confirmed that the indirect effect was significant, $M=0.50, S E=0.20,95 \%$ biascorrected confidence interval $[0.18,0.98]$.

External Observers' Ratings. Interactions were shorter in the Hide condition $(M=172$ seconds, $S D=51$ seconds) than in the Reveal condition ( $M=212$ seconds, $S D=81$ seconds), $t(46)=-$ 2.06, $p=.045, d=0.61$. Participants talked less in the Hide condition $(M=68$ seconds, $S D=44$ seconds) than in the Reveal condition ( $M=104$ seconds, $S D=72$ seconds), $t(46)=-2.06, p=.045$, $d=0.61$. Total interaction duration and participant talk time were nearly perfectly correlated, $r(46)=.99, p<.001$. Confederate talk time $(M=51 \text { seconds, } S D=10 \text { seconds })^{7}$ did not differ between conditions, $p=.551$, and was only weakly correlated with total interaction duration, $r(46)=.24, p=.098$. Thus, consistent with the prediction that hiding a stigmatized identity would curb self-disclosure at a general level, participants who hid (vs. revealed) a devalued identity talked less during the interaction, and this difference led to shorter interactions.

We examined external observers' perceptions of the participant and the interaction. External observers thought that participants self-disclosed less in the Hide condition $(M=3.35$, $S D=0.81)$ than in the Reveal condition $(M=3.96, S D=1.32), t(46)=-1.95, p=.057, d=0.58$, as predicted. Also as predicted, participants were rated somewhat (i.e., marginally) less positively 
in the Hide condition $(M=4.16, S D=0.69)$ than in the Reveal condition $(M=4.57, S D=0.90)$, $t(46)=-1.76, p=.085, d=0.52$. The interactions were evaluated less positively in the Hide condition $(M=4.04, S D=0.76)$ than in the Reveal condition $(M=4.48, S D=0.78), t(46)=-1.96$, $p=.056, d=0.58$.

We hypothesized that the effect of experimental condition on external observers' evaluations of the interaction and the participant would be mediated by the extent to which observers perceived the participant to self-disclose. When experimental condition and perceived disclosure were simultaneously entered as predictors of evaluation of the interaction, perceived disclosure was a significant predictor, $p<.001$, whereas the effect of experimental condition was nonsignificant, $p=.345$ (see Figure 2). Similarly, when experimental condition and perceived disclosure simultaneously predicted evaluation of the participant, perceived disclosure was a significant predictor, $p<.001$, whereas the effect of experimental condition was nonsignificant, $p=.419$ (see Figure 2). Bootstrapping (with 5000 resamples) confirmed that perceived disclosure mediated the effect of experimental condition on evaluation of both the interaction, $M=0.26$, $S E=0.14,95 \%$ bias-corrected confidence interval $[0.04,0.60]$, and the participant, $M=0.24$, $S E=0.13,95 \%$ bias-corrected confidence interval [0.01, 0.54].

\section{Discussion}

As hypothesized, Study 2 demonstrated that participants who anticipated hiding (vs. revealing) a contextually stigmatized identity during a face-to-face interaction experienced lack of belonging. Importantly, this experience did not occur merely "in their heads"; it was also detected by external observers, who rated these participants' interactions with the confederate as less positive and had less positive impressions of the participants themselves-indicators of reduced levels of actual acceptance during the interaction. Ironically, then, although people living with concealable stigmatized identities may hide their true identities in an attempt to 
increase belonging and acceptance (as suggested by Studies 1a and 1b; see also Garcia \& Crocker, 2008; Goffman, 1963), our results demonstrate that in so doing they end up both feeling and being excluded.

Study 2 further showed that expecting to enter an interaction during which one would hide a devalued identity lowered feelings of belonging because it limited the extent to which participants anticipated they would be able to be authentic, or true to themselves. This was the case despite the fact that, contrary to hiding, revealing a stigmatized identity directs attention to only one aspect of oneself, and often an aspect that one does not find central to one's identity. From external observers' perspective, hiding a devalued identity resulted in interactions lacking in belonging and acceptance because hiding lead participants to self-disclose less—behavior that encourages rejection (Herek, 1996). Notably, these effects emerged despite the external observers being blind to study design and thus entirely unaware of the fact that participants possessed a devalued identity. Whereas authenticity (and perhaps also self-disclosure) may be seen as closely related to the act of hiding a devalued identity, our primary hypothesis involved belonging and acceptance, ultimate outcome variables that are in no way redundant with the act of hiding (vs. revealing) a stigmatized identity. In summary, Study 2 revealed that hiding a devalued identity from an interaction partner not only reduces one's sense of belonging already in anticipation of the interaction; it also results in interactions that are perceived by external onlookers as less positive and as lacking in behaviors that typically elicit interpersonal closeness and acceptance.

The fact that we examined a contextually devalued identity that is not typically stigmatized leaves open the possibility that the processes implicated in Study 2 may not straightforwardly generalize to the experiences of individuals living with concealable identities 
that are culturally stigmatized. Thus, in Study 3 we again focused on a culturally stigmatized identity: having a history of mental illness.

\section{Study 3}

Thus far, we have demonstrated that although individuals expect to benefit interpersonally from hiding (vs. revealing) a devalued identity (Studies 1a and 1b), the act of hiding a stigmatized identity during a social interaction in fact results in lack of belonging (Study 2). In Study 3, our aim was to examine the impact of hiding a devalued identity on one's partner's perceptions of the interaction. As noted by West (2011), the dynamics of interpersonal interactions cannot be fully understood without taking into account the interdependent perspectives of both (or all) interaction partners. Accordingly, whereas the use of confederates in Study 2 ensured that interaction partners behaved in a standardized manner across conditions, in Study 3 we investigated face-to-face interactions between a non-stigmatized and a stigmatized participant. The stigmatized participant either hid or revealed their identity.

Specifically, in Study 3 we focused on the concealable stigmatized identity of having a history of mental illness. People who have a history of mental illness are strongly stigmatized: They are perceived as incompetent, unsuccessful, unintelligent, awkward, cold, and even dangerous (Farina, Fischer, Boudreau, \& Belt, 1996; Sibicky \& Dovidio, 1986). Individuals with a history of mental illness expect to be devalued and discriminated against (Link, 1987) and indeed are treated highly negatively in interpersonal interactions merely because of their devalued identity (Farina, Holland, \& Ring, 1966; Sibicky \& Dovidio, 1986). Believing that others know about one's history of mental illness leads individuals to behave in ways that cause them to be socially rejected (even when that belief is inaccurate; Farina, Gliha, Boudreau, Allen, $\&$ Sherman, 1971; and even when one does not actually have a history of mental illness; Farina, 
Allen, \& Saul, 1968). Revealing one's history of mental illness is so threatening that it can impair cognitive performance (Quinn et al., 2004).

Despite these severe ramifications associated with revealing a history of mental illness, we hypothesized that hiding this identity would impair one's sense of authenticity, and may limit the degree to which one's partner experiences a sense of intimacy during the interaction. That is, although the strong stigmatization of mental illness may suggest that hiding this identity might be highly preferable over revealing it, we hypothesized that hiding one's true identity would even in this case impair the interaction in important ways. Thus, in Study 3, participants who had a history of mental illness ("stigmatized" participants) interacted with participants who did not have a history of mental illness ("non-stigmatized" participants), ${ }^{8}$ and were randomly assigned to either hide or reveal their history of mental illness. We predicted that stigmatized participants would report more negative expectations prior to an interaction during which they would reveal (vs. hide) their identity; such a finding would conceptually replicate Studies $1 \mathrm{a}$ and $1 \mathrm{~b}$, and would again suggest that individuals expect to benefit interpersonally from keeping their devalued identities hidden from interaction partners. However, we also predicted that stigmatized participants who hid (vs. revealed) their identities would subsequently report reduced authenticity. In addition, we assessed the extent to which non-stigmatized participants experienced intimacy during the interaction, and expected to find that interacting with a stigmatized partner who hid (vs. revealed) their true identity would impair the extent to which non-stigmatized participants experienced intimacy during the interaction. This result would indicate that hiding a stigmatized identity from a cross-group partner disrupts rapport-building during a social interaction.

\section{Method}


Participants. Forty-two same-gender dyads (total N=84; 74 women, 10 men; mean age $=21.40, S D=3.81$ ) of student participants completed the study in return for $€ 4.50$. In each dyad, one participant was non-stigmatized (did not have a history of mental illness), and one participant was stigmatized (had a history of mental illness; e.g., depression, eating disorder). Non-stigmatized participants were recruited from a pool of student volunteers for psychology studies. Stigmatized participants were contacted because they had indicated during a prior study that they had a history of mental illness and had agreed to being contacted regarding participation in future studies, or were recruited via online advertisements, posters, and handouts. Stigmatized participants knew that their history of mental illness was the reason they were recruited. All stigmatized participants reported having a history of mental health issues that had significantly influenced their life; $69 \%$ reported having had treatment for these issues.

Design, Procedure, and Measures. The study complied with the standards for ethical psychological research endorsed at Leiden University, where the data were collected. Stigmatized and non-stigmatized participants began the study in separate rooms, in which they read and signed an informed consent form and received initial instructions (presented on a computer). As in Study 2, participants were told that one participant in each dyad would be randomly assigned to an "interviewer" role and the other to an "interviewee" role. In reality, stigmatized participants were always interviewees and non-stigmatized participants were always interviewers.

Non-stigmatized participants were simply told that they would be asked to interview another participant, with the aim of studying social interactions; the partner's history of mental illness was not mentioned. They were given a series of interview questions but were not given further instructions on how to conduct the interview. Participants then responded to three items 
assessing negative expectations regarding the upcoming interaction $(1=$ completely disagree to 7=completely agree): "I feel uncomfortable with the idea that I must undergo this interaction"; "I look forward to the interaction" (reverse-scored); and "I would prefer not to undergo this interaction" $(\alpha=.75)$.

In contrast, stigmatized participants were told that the study examined social interactions between a person with and a person without a history of mental illness and, specifically, prejudice against people with a history of mental illness. Stigmatized participants were reminded that people with a history of mental illness are often perceived by others as less social and less competent. During debriefing, participants were informed about the purpose of this procedure. Stigmatized participants were next told that there are two ways of responding to prejudice, namely revealing or hiding one's stigmatized identity, and that the present study aimed to understand both responses. At this point, participants were randomly assigned to one of two conditions. In the Hide condition $(N=20)$, participants were asked "not to reveal to the other participant" that they had a history of mental illness, whereas in the Reveal condition $(N=22)$, participants were asked "to reveal to the other participant" that they had a history of mental illness. In order to elicit active agreement to hide (or reveal) the stigmatized identity, participants were asked to indicate their agreement to follow these instructions by pressing an "OK" button to continue; all participants chose to continue with the study. Participants then completed the same three-item measure of negative expectations as did non-stigmatized participants $(\alpha=.89)$.

The experimenter next led participants to a lab outfitted with video recording equipment and the interaction took place. Non-stigmatized participants conducted the interview based on a script. The questions were initially neutral (e.g., "Is this the first time you are participating in a psychology experiment?") but became increasingly relevant to mental illness (e.g., "Do you have 
the feeling your life is like a roller coaster, with lots of ups and downs?"; "Do you sometimes feel like you are different from other people?"; for a similar procedure, see Smart \& Wegner, 1999). The final question directly inquired whether the interviewee had a history of mental illness. The interactions lasted approximately seven minutes on average ( $M=427$ seconds, $S D=280$ seconds; measured by the experimenter).

All participants finally completed post-interaction measures (1=completely disagree to $7=$ completely agree $)$. Three items measured the degree to which participants felt they had been authentic during the interaction: "I felt honest"; "I felt trustworthy"; and "I felt I acted in accordance with my conscience" ( $\alpha=.87$ for stigmatized participants; $\alpha=.66$ for non-stigmatized participants). Nine items measured the extent to which participants had experienced intimacy with their interaction partner (e.g., "My conversation partner and I clicked"; "I feel connected to my conversation partner"; $\alpha=.83$ for stigmatized participants; $\alpha=.90$ for non-stigmatized participants).

\section{Results}

Because the study had a nested design in which participants were nested within interaction dyads, we treated dyads as the unit of analysis in order to adjust for potential nonindependence in participants' responses (following the recommendations regarding the analysis of dyadic data given in Kenny, Kashy, \& Cook, 2006). Both stigmatized and nonstigmatized participants provided ratings of their own experiences before and during the interaction (i.e., measures of negative expectations, authenticity, and intimacy), allowing us to examine both participants' perspectives on the interactions.

Pre- and Post-Interaction Affective Reactions. Both stigmatized and non-stigmatized participants reported their own levels of negative expectations in anticipation of the interaction, 
as well as the degree to which they themselves had felt authentic during the interaction (measured after the interaction had taken place). We first examined whether these self-ratings varied between conditions for either subgroup of participants.

A 2 (Condition: Hide vs. Reveal) $\times 2$ (Participant: Stigmatized vs. Non-stigmatized) mixed-model ANOVA on participants' self-reported negative expectations in anticipation of the interaction, with dyad as the unit of analysis and the second factor varying within-dyad (see Kenny et al., 2006), revealed a nonsignificant main effect of Condition, $p=.178$, a significant main effect of Participant, $F(1,40)=5.97, p=.019, \eta_{p}^{2}=.13$, and the predicted interaction, $F(1$, $40)=4.50, p=.040, \eta_{p}^{2}=.10$. Analysis of simple effects (following the recommendations of Howell, 2002) demonstrated that whereas stigmatized $(M=3.35, S D=1.44)$ and non-stigmatized participants $(M=3.27, S D=1.10)$ did not differ in the degree to which they reported having negative expectations in the Hide condition, $p=.821$, in the Reveal condition stigmatized participants reported more negative expectations $(M=4.32, S D=1.50)$ than did non-stigmatized participants $(M=3.14, S D=1.09), F(1,21)=10.34, p=.004$. Stated differently, whereas stigmatized participants reported more negative expectations in the Reveal (vs. Hide) condition, $F(1$, $78)=5.85, p=.018$, non-stigmatized participants' negative expectations did not differ between conditions, $p=.746$. Thus, as hypothesized and conceptually replicating the findings observed in Studies 1a and 1b, stigmatized participants about to enter an interaction in which they would reveal their history of mental illness to a partner who did not share this stigmatized identity reported high levels of negative expectations.

Second, a mixed-model ANOVA on the degree to which participants reported having felt authentic during the interaction revealed a main effect of Condition, $F(1,40)=12.12, p=.001$, $\eta_{p}^{2}=.23$, and a main effect of Participant, $F(1,40)=19.79, p<.001, \eta_{p}^{2}=.33$, qualified by the 
predicted interaction, $F(1,40)=8.08, p=.007, \eta_{p}^{2}=.17$. Analysis of simple effects demonstrated that whereas stigmatized $(M=5.70, S D=0.85)$ and non-stigmatized participants $(M=6.06$, $S D=0.80$ ) did not report different levels of authenticity in the Reveal condition, $p=.168$, in the Hide condition stigmatized participants reported having experienced less authenticity $(M=4.27$, $S D=1.63)$ than did non-stigmatized participants $(M=5.92, S D=0.58), F(1,19)=18.51, p<.001$. Stated differently, whereas stigmatized participants reported having experienced less authenticity in the Hide (vs. Reveal) condition, $F(1,80)=19.99, p<.001$, non-stigmatized participants experienced similar levels of authenticity in both conditions, $p=.654$. Thus, as hypothesized, stigmatized participants who had concealed their history of mental illness from an interaction partner reported low levels of authenticity.

Intimacy. We next examined the degree to which participants experienced intimacy with their partner. Here, we expected to find effects primarily among non-stigmatized participants; that is, we expected that the degree to which non-stigmatized participants experienced intimacy with their partner would depend on whether the partner had concealed or revealed their history of mental illness. In particular, we predicted that non-stigmatized participants would experience more intimacy when their partner revealed their stigmatized identity. Stated differently, we predicted that concealing a stigmatized identity would disrupt intimacy- and rapport-building during the interaction. Unexpectedly, however, a 2 (Condition: Hide vs. Reveal) $\times 2$ (Participant: Stigmatized vs. Non-stigmatized) mixed-model ANOVA on intimacy revealed no significant effects, $p \mathrm{~s} \geq .233$. We therefore conducted follow-up analyses in order to understand this unexpected pattern in greater detail.

Specifically, in these exploratory analyses we sought to take into account the fact that stigmatized participants had experienced differing levels of negative affect (i.e., negative 
expectations and inauthenticity) based on whether they had concealed or revealed their history of mental illness during the interaction. Both negative expectations (experienced in particular in the Reveal condition) and inauthenticity (experienced in particular in the Hide condition) likely affected the degree to which stigmatized participants experienced intimacy during the interaction; however, these psychological processes worked in opposite directions across the two conditions and may thus have canceled each other out in the analysis. Given that intimacy is in essence an interpersonal process (Reis \& Shaver, 1988), non-stigmatized participants' levels of intimacy were likely also affected by their stigmatized partners' different experiences in the two conditions.

To test this exploratory possibility, we examined levels of intimacy among stigmatized and non-stigmatized participants in the two experimental conditions while statistically adjusting for both participants' levels of negative expectations and authenticity (i.e., holding these variables constant at their respective means). Accordingly, we estimated an actor-partner interdependence model (Kenny et al., 2006). As predictors, we entered Condition (Hide=-1, Reveal=1), Participant (Non-stigmatized=-1, Stigmatized=1), and their interaction; as adjustment variables (each continuous and mean-centered), we entered participants' own negative expectations, their partners' negative expectations, participants' own authenticity, and their partners' authenticity (see Table 1). This model thus held constant (i.e., statistically removed) the influence of participants' own affective responses, as well as the influence of their partners' affective responses, on feelings of intimacy.

In this analysis (see Table 1 and Figure 3), the expected Condition (Hide vs. Reveal) $\times$ Participant (Stigmatized vs. Non-stigmatized) interaction was obtained, $b=-0.26, S E=0.10$, $t(39.21)=-2.66, p=.011$. Simple slopes analyses revealed that within the Hide condition, non- 
stigmatized participants experienced significantly less intimacy than did stigmatized participants, $b=0.38, S E=0.15, t(39.43)=2.51, p=.016$. In contrast, within the Reveal condition, nonstigmatized and stigmatized participants experienced similar levels of intimacy, $p=.307$. Stated differently, non-stigmatized participants tended to experience somewhat, though nonsignificantly, less intimacy when their stigmatized partner concealed (vs. revealed) their history of mental illness, $b=0.31, S E=0.21, t(45.85)=1.45, p=.155$. In contrast, and as anticipated, there was no effect of experimental condition on stigmatized participants' experiences of intimacy, $p=.231 .^{9}$

\section{Discussion}

Study 3 revealed that participants about to enter an interaction in which they would reveal their history of mental illness to a partner who did not share this stigmatized identity reported particularly high levels of negative expectations. In contrast, participants who hid their history of mental illness from their partner reported particularly low levels of felt authenticity after the interaction. These findings illustrate the quandary faced by individuals who hide a stigmatized identity: Hiding one's identity may be a common coping strategy because it reduces anxiety in anticipation of stigmatization by others, likely because one expects to thereby be able to avoid the negative interpersonal consequences of revealing the identity (see also Studies 1a and 1b). However, this strategy may be maladaptive insofar as it is associated with states of inauthenticity (which are aversive and negatively correlated with wellbeing; Lenton et al., 2013; Wood et al., 2008). Our results extend those of Barreto et al. (2006), who found that although hiding (vs. revealing) a devalued identity led people to believe that their interaction partners had more positive expectations regarding their performance (which should reduce stereotype threat), it also decreased self-confidence (which nullified the positive impact of improved expectations). 
Thus, the anticipated benefits of concealing a devalued identity are significantly offset by the ramifications of the act of hiding.

Going beyond past research, Study 3 also illustrated the multifaceted interpersonal consequences of hiding a stigmatized identity. Unlike Study 2, in which we measured belonging in anticipation of a social interaction, in Study 3 we measured participants' experiences of intimacy after the interaction had taken place. Accordingly, stigmatized participants in Study 3 already knew how the interaction had gone-and notably, we still did not observe a pattern implying a benefit associated with hiding a devalued identity (i.e., stigmatized participants' felt intimacy did not differ between conditions), even though stigmatized individuals expect such a benefit (see Studies 1a and 1b). Conversely, it may also be the case that stigmatized participants who revealed their history of mental illness may have been surprised, or relieved, to find that their negative expectations in anticipation of the interaction were not realized; such processes may also have contributed to the lack of effects on intimacy among stigmatized participants. Future work may benefit from directly examining these possibilities.

However, we did find that the act of hiding a devalued identity impaired the degree to which one's partner experienced intimacy during the interaction. Interestingly, this effect was only observed when both participants' levels of negative expectations and authenticity were statistically controlled, suggesting that the distinct negative experiences caused by the two experimental conditions, particularly among stigmatized participants, may have differentially disrupted rapport- and intimacy-building processes during the interaction. Supplementary analyses revealed that whereas participants' own feelings of intimacy were strongly positively correlated with their partners' feelings of intimacy in the Reveal condition, $r(20)=.64, p=.001$, this association was substantially weaker and nonsignificant in the Hide condition, $r(18)=.13$, 
$p=.588$; the difference between these two correlations approached significance, $z=1.88, p=.060$. Thus, our findings suggest that stigmatized participants' limited authenticity (that was experienced specifically in the Hide condition) may have resulted in a disconnect between their own and their non-stigmatized partners' experiences of intimacy.

Notably, this nuanced pattern emerged even though hiding could conceivably have been viewed as a strongly preferable identity management strategy due to the severe stigmatization of mental illness. Relatedly, stigmatized participants in Study 3 were told that the study investigated prejudice against people with a history of mental illness. However, interactions in which stigmatized participants expected to reveal, and in the final interview question were directly asked to reveal, their history of mental illness were not impaired, as suggested by the strong positive association between one's own and one's partner's sense of intimacy in the Reveal condition; rather, it was hiding this identity that served to disrupt the interaction.

Importantly, we observed a consistent pattern of results across Study 2, in which we studied a contextually (as opposed to culturally) devalued identity, and Study 3, in which we studied an identity that is strongly culturally devalued. This consistency suggests that the interpersonal ramifications of hiding a stigmatized identity are robust, even when the stigma is particularly strong and even when the context might be particularly unwelcoming to revealing the identity, and implies a good degree of generalizability to a variety of different identities and situations that stigmatized individuals may experience in their everyday lives. Accordingly, although hiding a stigmatized identity is a common identity management strategy, it may not be adaptive in the long run: Rather than allowing the individual to "fit in," hiding one's true identity has a variety of negative interpersonal consequences.

\section{General Discussion}


Hiding a socially stigmatized identity is expected to secure acceptance and belonging, and is therefore an identity management strategy frequently used by individuals living with concealable stigmatized identities (Goffman, 1963; Jones et al., 1984; Katz, 1981). The present research, however, showed that hiding a stigmatized identity has the ironic effect of actually decreasing feelings of belonging. Four studies, carried out in different settings, focusing on a variety of stigmatized identities, taking the perspectives of the stigmatized target, of external observers, and of non-stigmatized interaction partners both before, during, and after the interaction, and employing diverse operationalizations of belonging and other interpersonal outcomes, demonstrated that although individuals living with stigmatized identities expect to benefit interpersonally from hiding the identity from interaction partners, hiding in fact reduces belonging compared to when the identity is revealed. Whereas each of the studies has limitations when considered in isolation, the strength of the present research emerges from the converging results obtained across divergent conceptualizations and operationalizations of the key constructs, and across different research paradigms, stigmatized identities, and participant samples.

Specifically, Studies 1a and 1b showed that participants who imagined a social interaction occurring within a workplace context reported that they would choose to hide (rather than reveal) their stigmatized identities and expected that revealing the identity would result in a negative impact on their workplace relationships. Study 2 focused on an experimentally elicited stigma (i.e., an identity that was contextually, though not culturally, devalued) and revealed that hiding reduced belonging because it impaired authenticity, constraining the expression of one's true self. Importantly, Study 2 also considered the perspective of external observers, and demonstrated that those who hid (vs. revealed) a stigmatized identity were less liked, and their 
interactions with others were less positively evaluated, by external onlookers. In addition, Study 2 showed that these effects emerged because individuals who hid a stigmatized identity were perceived to engage in fewer intimacy-building behaviors (i.e., self-disclosure), compared to those who revealed the identity. Study 3 extended these findings by examining the interdependent perspectives of stigmatized and non-stigmatized participants. Study 3 confirmed that hiding a devalued identity can indeed lead one to have more positive expectations about upcoming interactions (conceptually replicating Studies 1a and 1b), but that it ironically also results in lower feelings of authenticity during the interaction and impairs intimacy-building with one's non-stigmatized interaction partner (though we note that this last finding only emerged when we statistically controlled for negative expectations and feelings of authenticity).

Taken together, these four studies indicate that hiding a socially stigmatized identity is a problematic identity management strategy in that it is expected to provide, but does not deliver, the social acceptance much sought by individuals living with stigmatized identities. Future work may benefit from seeking to understand the consequences of the unfulfilled promises of concealing a devalued identity. For example, individuals who typically hide their devalued identities and yet consistently fail to experience belonging and acceptance may begin to develop more nuanced strategies for concealing their identities, perhaps prioritizing opportunities for positive self-presentation. Understanding the extent to which alternative ways of hiding a stigmatized identity may have different intraindividual and interpersonal consequences represents an important direction for future research, and has practical implications for the lives of individuals contending with stigmatization.

Moreover, the present results underscore the importance of not assuming, and instead carefully investigating, the degree to which different identity management strategies fulfill their 
anticipated goals. Indeed, research examining the psychological processes associated with stigmatized individuals' acts of coping is scarce, and existing knowledge regarding the predicament of those living with stigmatized identities is thus incomplete in important ways. Our results begin to illuminate how coping with a concealable stigmatized identity is subject to ironic processes stemming from a mismatch between expected and actual interpersonal consequences. Furthermore, much of the available research in this domain, while informative in several ways, has tended to employ non-experimental methods that do not allow for the confident identification of causal mechanisms (e.g., Quinn \& Chaudoir, 2009). Such lack of causal evidence is particularly problematic when, as in the present case, the opposite direction of causality would at first sight seem more plausible: Only experimental methods allow for the conclusion that hiding a socially stigmatized identity causes reduced belonging, as opposed to (also plausibly) it primarily being individuals who experience lack of belonging who most often hide their identities.

Although we believe that the present results offer important novel insights into the experiences of individuals living with concealable stigmatized identities, we acknowledge limitations and caveats. First, although Studies 1a and 1b examined participants' preference for hiding (vs. revealing) a stigmatized identity when given the choice between the two identity management strategies and demonstrated that participants would indeed choose to hide their identities, the experimental manipulations of hiding (vs. revealing) a devalued identity employed in Studies 2 and 3 did not similarly give participants a fully free choice. In part, this reflects the necessities of experimental design and the need for random assignment to conditions. However, this feature of Studies 2 and 3 implies that the additional question of whether the free choice to hide or reveal one's devalued identity makes a difference to interpersonal consequences and the 
outcomes of a social interaction remains unanswered. Future work might productively address this issue for instance by including a third condition in which participants are given the choice to either hide or reveal their identities. Although we anticipate that most participants in this "choice" condition would likely opt to hide the identity—an expectation that is strongly supported by the results of Studies $1 \mathrm{a}$ and $1 \mathrm{~b}$ — and that the consequences of hiding would not differ based on whether the act of hiding occurred entirely based on participants' voluntary choice, we note that further empirical work is needed to confirm these hypotheses within a single paradigm. ${ }^{10}$ Nevertheless, the four studies we report in the present work do converge to support the notion that although individuals living with devalued identities expect that concealing the identity is a beneficial strategy (Studies $1 \mathrm{a}$ and $1 \mathrm{~b}$ ), these expected benefits of concealment are not realized in actual social interactions (Studies 2 and 3). We note, however, that the situations we examined in the present work were such that the feared negative expectations regarding revealing a stigmatized identity were generally not borne out. Future research may thus productively consider identity management strategies in the face of explicit social rejection due to being revealed as stigmatized - a situation which remains unfortunately commonplace in the experience of individuals living with stigmatized identities.

Moreover, we acknowledge that the present set of studies do not establish whether our findings are specific to hiding a stigmatized identity, or whether they might rather be more generally related to concealing aspects of the self, or even more generally to being untruthful to an interaction partner. However, while these distinctions are important and represent another interesting direction for future work, our conceptual framework does not rely on the hypothesized and demonstrated processes being specific to hiding a stigmatized identity. Rather, we have sought to demonstrate that hiding one's true identity during social interactions involves 
being untruthful—both to oneself (as illustrated by our findings related to authenticity) and to one's interaction partners-which makes concealment interpersonally detrimental (contrary to its anticipated beneficial impact).

In conclusion, the present research illuminates the complexities of identity management among individuals living with concealable stigmatized identities. Given its benefits (e.g., protection from bias and stereotype threat; Quinn et al., 2004), as well as important costs (as revealed in the present work), deciding whether or not to cope with a stigmatized identity by hiding it from others is a central and consequential dilemma in the lives of individuals who are stigmatized. Individuals living with stigmatized identities must thus consider the relative costs and benefits of different identity management strategies, at times facing high costs of revealing their true identities (e.g., being fired) while also contending with the very tangible interpersonal costs of concealing their identities (as demonstrated in the present work). This tradeoff dilemma, moreover, is one with which non-stigmatized individuals never need to contend, revealing yet another way in which social stigma creates and perpetuates disadvantage and inequality. It is important to note, however, that the situation examined in the present work was not one in which stigma was likely to have extreme consequences, such as aggression or even death.

Circumstances in which such extreme consequences are more likely (e.g., living in a society in which homosexuality is punished with the death penalty) dictate a change of balance between costs and benefits that render the choice of identity management strategy exceedingly clear. Even in such circumstances, though, the interpersonal costs of hiding a stigmatized identity revealed in the present work may emerge; despite the highly reasonable choice of concealing one's true identity in such a context, that choice may regardless imply loss of authenticity, increased selfmonitoring and the resulting limited self-disclosure, and the potential for social rejection. Future 
research may thus productively seek to unveil whether and how, when hiding a stigmatized identity is inevitable, this coping strategy might be engaged in without such repercussions. 


\section{References}

Barreto, M., \& Ellemers, N. (2003). The effects of being categorised: The interplay between internal and external social identities. European Review of Social Psychology, 14, 139170.

Barreto, M., Ellemers, N., \& Banal, S. (2006). Working under cover: Performance-related selfconfidence among members of contextually devalued groups who try to pass. European Journal of Social Psychology, 36, 337-352.

Buhrmester, M., Kwang, T., \& Gosling, S. D. (2011). Amazon's Mechanical Turk: A new source of inexpensive, yet high-quality, data? Perspectives on Psychological Science, 6, 3-5.

Chaudoir, S. R., \& Fisher, J. D. (2010). The Disclosure Processes Model: Understanding disclosure decision making and postdisclosure outcomes among people living with a concealable stigmatized identity. Psychological Bulletin, 136, 236-256.

Cole, S. W., Kemeny, M. E., Taylor, S. E., \& Visscher, B. R. (1996). Elevated physical health risk among gay men who conceal their homosexual identity. Health Psychology, 15, 243251.

Collins, N. L., \& Miller, L. C. (1994). Self-disclosure and liking: A meta-analytic review. Psychological Bulletin, 116, 457-475.

Crocker, J., Major, B., \& Steele, C. (1998). Social stigma. In D. Gilbert, S. T. Fiske, \& G. Lindzey (Eds.), Handbook of social psychology (4th Ed., pp. 504-553). New York, NY: McGraw-Hill.

Farina, A., Allen, J. G., \& Saul, B. B. B. (1968). The role of the stigmatized in affecting social relationships. Journal of Personality, 36, 169-182. 
Farina, A., Fischer, E. H., Boudreau, L. A., \& Belt, W. E. (1996). Mode of target presentation in measuring the stigma of mental disorder. Journal of Applied Social Psychology, 26, $2147-2156$.

Farina, A., Holland, C. H., \& Ring, K. (1966). The role of stigma and set in interpersonal interaction. Journal of Abnormal Psychology, 71, 421-428.

Farina, A., Gliha, D., Boudreau, L. A., Allen, J. G., \& Sherman, M. (1971). Mental illness and the impact of believing others know about it. Journal of Abnormal Psychology, 77, 1-5.

Frable, D. E., Blackstone, T., \& Scherbaum, C. (1990). Marginal and mindful: Deviants in social interactions. Journal of Personality and Social Psychology, 59, 140-149.

Frable, D. E., Platt, L., \& Hoey, S. (1998). Concealable stigmas and positive self-perceptions: Feeling better around similar others. Journal of Personality and Social Psychology, 74, 909-922.

Garcia, J. A., \& Crocker, J. (2008). Reasons for disclosing depression matter: The consequences of having egosystem and ecosystem goals. Social Science and Medicine, 67, 453-462.

Goffman, E. (1963). Stigma: Notes on the management of a spoiled identity. Englewood Cliffs, NJ: Prentice-Hall.

Hayes, A. F. (2013). Introduction to mediation, moderation, and conditional process analysis: A regression-based approach. New York, NY: Guilford Press.

Herek, G. M. (1996). Why tell if you are not asked? Self-disclosure, intergroup contact, and heterosexuals' attitudes toward lesbians and gay men. In G. M. Herek, J. B. Jobe, \& R. M. Carney (Eds.), Out in force: Sexual orientation in the military (pp. 197-225). Chicago, IL: University of Chicago Press.

Howell, D. C. (2002). Statistical methods for psychology (5th Ed.). Pacific Grove, CA: Duxbury. 
Jones, E. E., Farina, A., Hastorf, A. H., Markus, H., Miller, D. T., \& Scott, R. A. (1984). Social stigma: The psychology of marked relationships. New York, NY: Freeman.

Katz, I. (1981). Stigma: A social psychological analysis. Hillsdale, NJ: Lawrence Erlbaum.

Kelly, A. E., \& McKillop, K. J. (1996). Consequences of revealing personal secrets. Psychological Bulletin, 120, 450-465.

Kenny, D. A., Kashy, D. A., \& Cook, W. L. (2006). Dyadic data analysis. New York, NY: Guilford Press.

Leary, K. (1999). Passing, posing, and "keeping it real.” Constellations, 6, 85-96.

Lenton, A. P., Bruder, M., Slabu, L., \& Sedikides, C. (2013). How does "being real” feel? The experience of state authenticity. Journal of Personality, 81, 276-289.

Link, B. G. (1987). Understanding labeling effects in the area of mental disorders: An assessment of the effects of expectations of rejection. American Sociological Review, 52, $96-112$

Major, B., \& Gramzow, R. H. (1999). Abortion as stigma: Cognitive and emotional implications of concealment. Journal of Personality and Social Psychology, 77, 735-745.

Meyer, I. H. (2003). Prejudice, social stress, and mental health in lesbian, gay, and bisexual populations: Conceptual issues and research evidence. Psychological Bulletin, 129, 674697.

Quinn, D. M., \& Chaudoir, S. R. (2009). Living with a concealable stigmatized identity: The impact of anticipated stigma, centrality, salience, and cultural stigma on psychological distress and health. Journal of Personality and Social Psychology, 97, 634-651. 
Quinn, D. M., Kahng, S. K., \& Crocker, J. (2004). Discreditable: Stigma effects of revealing a mental illness history on test performance. Personality and Social Psychology Bulletin, $30,803-815$

Ragins, B. R., Singh, R., \& Cornwell, J. M. (2007). Making the invisible visible: Fear and disclosure of sexual orientation at work. Journal of Applied Psychology, 92, 1103-1118.

Reis, H. T., \& Shaver, P. (1988). Intimacy as an interpersonal process. In S. Duck (Ed.), Handbook of personal relationships (pp. 367-389). Chichester, UK: Wiley.

Rodriguez, R. R., \& Kelly, A. E. (2006). Health effects of disclosing secrets to imagined accepting versus nonaccepting confidants. Journal of Social and Clinical Psychology, 25, 1023-1047.

Schwartz, S. H. (1992). Universals in the content and structure of values: Theoretical advances and empirical tests in 20 countries. In M. P. Zanna (Ed.), Advances in experimental social psychology (Vol. 25, pp. 1-65). New York, NY: Academic Press.

Sibicky, M., \& Dovidio, J. F. (1986). Stigma of psychological therapy: Stereotypes, interpersonal reactions, and the self-fulfilling prophecy. Journal of Counseling Psychology, 33, 148154.

Smart, L., \& Wegner, D. M. (1999). Covering up what can't be seen: Concealable stigma and mental control. Journal of Personality and Social Psychology, 77, 474-486.

Turner, R. N., Hewstone, M., \& Voci, A. (2007). Reducing explicit and implicit outgroup prejudice via direct and extended contact: The mediating role of self-disclosure and intergroup anxiety. Journal of Personality and Social Psychology, 93, 369-388. 
Van Lange, P. A., \& Sedikides, C. (1998). Being more honest but not necessarily more intelligent than others: Generality and explanations for the Muhammad Ali effect. European Journal of Social Psychology, 28, 675-680.

Waldo, C. R. (1999). Working in a majority context: A structural model of heterosexism as minority stress in the workplace. Journal of Counseling Psychology, 46, 218-232.

West, T. V. (2011). Interpersonal perception in cross-group interactions: Challenges and potential solutions. European Review of Social Psychology, 22, 364-401.

Wood, A. M., Linley, P. A., Maltby, J., Baliousis, M., \& Joseph, S. (2008). The authentic personality: A theoretical and empirical conceptualization and the development of the Authenticity Scale. Journal of Counseling Psychology, 55, 385-399. 


\section{Footnotes}

${ }^{1}$ We also considered responses separately among participants who possessed different stigmatized identities. Given the small number of participants who possessed an LGBT identity $(N=5)$ or reported a history of "invisible" physical health issues $(N=6)$, we did not examine responses separately within these groups. However, the pattern of responses observed in the full sample held among participants who reported having a history of mental illness $(N=17)$, who were more likely to report choosing to conceal (vs. reveal) their identity ( $M=5.65, S D=1.69$; significantly above the scale midpoint, $t(16)=4.01, p=.001)$; reported believing that revealing the identity would have a negative effect on their relationships at work $(M=2.88, S D=1.73$; significantly below the scale midpoint, $t(16)=-2.67, p=.017)$; and reported believing that concealing the identity would have no effect on their relationships at work $(M=4.24, S D=1.35$; not different from the scale midpoint, $t(16)=0.72, p=.482)$. Similarly, the pattern also held among participants who reported having personal experience with poverty $(N=21)$, who were more likely to report choosing to conceal (vs. reveal) their identity $(M=5.00, S D=1.98$; significantly above the scale midpoint, $t(20)=2.32, p=.031)$; reported believing that revealing the identity would have a negative effect on their relationships at work $(M=3.38, S D=1.16$; significantly below the scale midpoint, $t(20)=-2.44, p=.024)$; and reported believing that concealing the identity would have no effect on their relationships at work $(M=3.62, S D=1.02$; not different from the scale midpoint, $t(20)=-1.71, p=.104)$.

${ }^{2}$ This pattern was not further moderated by identity (LGBT, mental health issues, physical health issues, vs. poverty).

${ }^{3}$ This pattern was not further moderated by identity (LGBT, mental health issues, physical health issues, vs. poverty). 
${ }^{4}$ Individuals who hide a stigmatized identity may at times simply cover the identity (e.g., by not mentioning it), and at other times may more explicitly "pass" as members of nonstigmatized groups. Notably, these strategies are often not fully distinguishable. For example, people are typically assumed to belong to dominant social categories (e.g., heterosexual) unless they directly indicate otherwise (e.g., by revealing a non-heterosexual orientation). Accordingly, covering often implies passing. Additionally, when the identity is contextually relevant and thus explicitly inquired about (e.g., possessing required professional experience), the sole available strategies are passing and revealing (i.e., simply not mentioning one's true identity is impossible in such a situation). Because contexts in which covering and passing are not easily distinguishable are arguably more typical, in the present work we focused on "hiding" one's devalued identity (which can describe both covering and passing).

${ }^{5}$ Due to video equipment malfunction, external rater data are missing for three interactions in the Hide condition and five interactions in the Reveal condition.

${ }^{6}$ Interrater reliability for confederate talk time may be lower than for other duration measures because the camera was focused on the participant and away from the confederate.

${ }^{7}$ Total interaction duration is longer than participants' and confederates' talk time combined due to silences during the interactions.

${ }^{8}$ For clarity of expression, we refer to participants with a history of mental illness as "stigmatized" and participants without such history as "non-stigmatized." These labels refer to the cultural stigmatization of mental illness, not to the participants themselves. Furthermore, history of mental illness was the sole stigmatized identity assessed in this study; thus, "nonstigmatized" participants may have possessed other stigmatized identities. However, no other 
identities were made salient in this study, ensuring that all effects were associated with the stigma of mental illness.

${ }^{9}$ We also assessed participants' perceptions of how smoothly the interaction went (12 items, e.g., "The conversation went smoothly"; $\alpha \mathrm{s} \geq .92$ ). The same actor-partner interdependence model on this variable revealed a marginal Condition $\times$ Participant interaction, $p=.062$. The sole significant simple slope indicated that whereas stigmatized participants thought the interactions went more smoothly in the Hide (vs. Reveal) condition, $p=.029$, there was no effect of condition on non-stigmatized participants' ratings, $p=.967$. Accordingly, as anticipated, intimacy revealed a pattern that was distinct from mere perceptions of how smooth and easy the interaction was.

${ }^{10}$ We thank a reviewer for these insightful suggestions. 
Table 1. Unstandardized regression coefficients and significance tests from an actor-partner interdependence model predicting participants' intimacy with their interaction partner (Study 3).

\begin{tabular}{lllllll}
\hline Predictor & $b$ & $S E$ & $\mathrm{df}$ & $t$ & \\
& & & & & \\
\hline Own Negative Expectations & -0.02 & 0.08 & 53.41 & -0.22 & .826 \\
Partner's Negative Expectations & -0.11 & 0.09 & 68.65 & -1.23 & .222 \\
Own Authenticity & 0.21 & 0.11 & 46.09 & 1.98 & .053 \\
Partner's Authenticity & -0.16 & 0.12 & 62.42 & -1.34 & .184 \\
Condition (Hide=-1; Reveal=1) & 0.05 & 0.17 & 39.34 & 0.30 & .764 \\
Participant (Non-stigmatized=-1; Stigmatized=1) & 0.12 & 0.10 & 39.40 & 1.22 & .229 \\
Condition $\times$ Participant & -0.26 & 0.10 & 39.21 & -2.66 & .011 \\
& & & & & \\
\hline
\end{tabular}




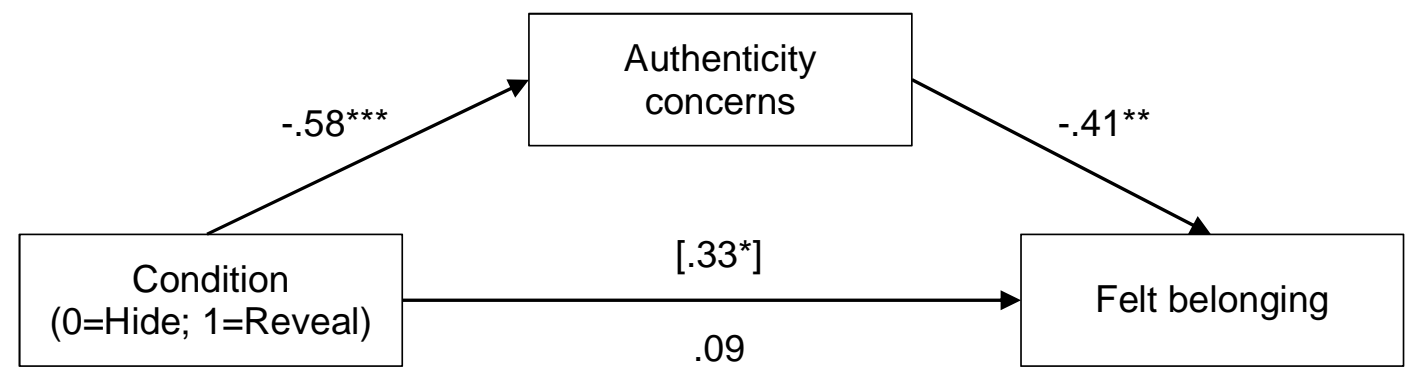

Figure 1 . The effect of hiding versus revealing a contextually stigmatized identity during a social interaction on feelings of belonging, mediated by concerns about authenticity (Study 2).

Standardized coefficients. ${ }^{*} p<.05 ;{ }^{* *} p<.01 ;{ }^{* * *} p<.001$ 
A

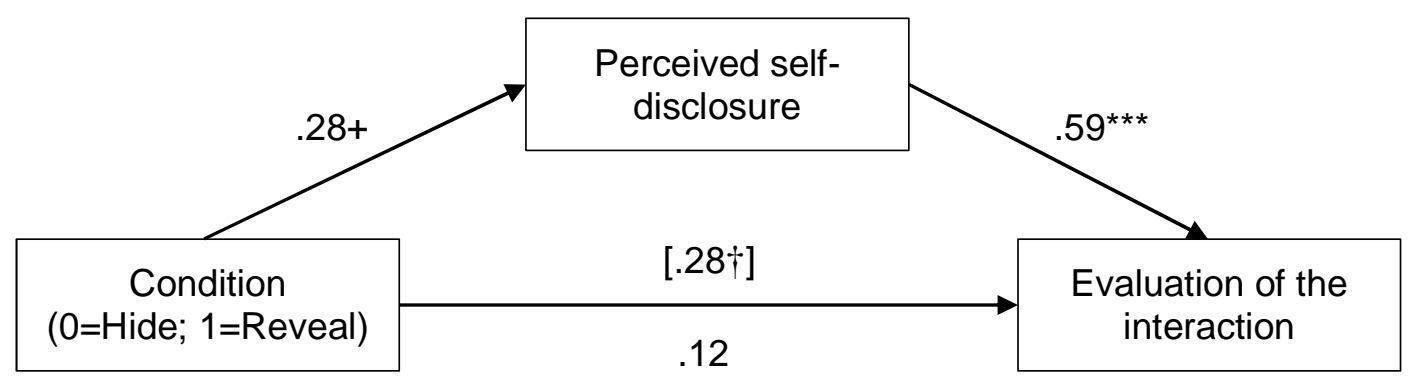

B

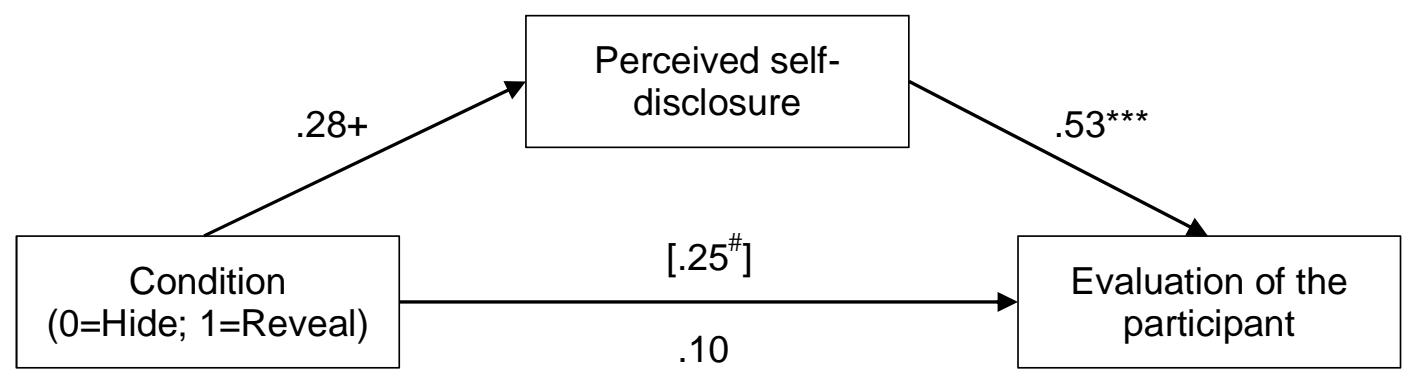

Figure 2. The effect of hiding versus revealing a contextually stigmatized identity during a social interaction on external observers' evaluations of (A) the interaction and (B) the participant, mediated by perceived self-disclosure (Study 2). Standardized coefficients. ${ }^{*} p=.085 ; \uparrow p=.056$; ${ }^{+} p=.057 ;{ }^{* * * *} p<.001$ 


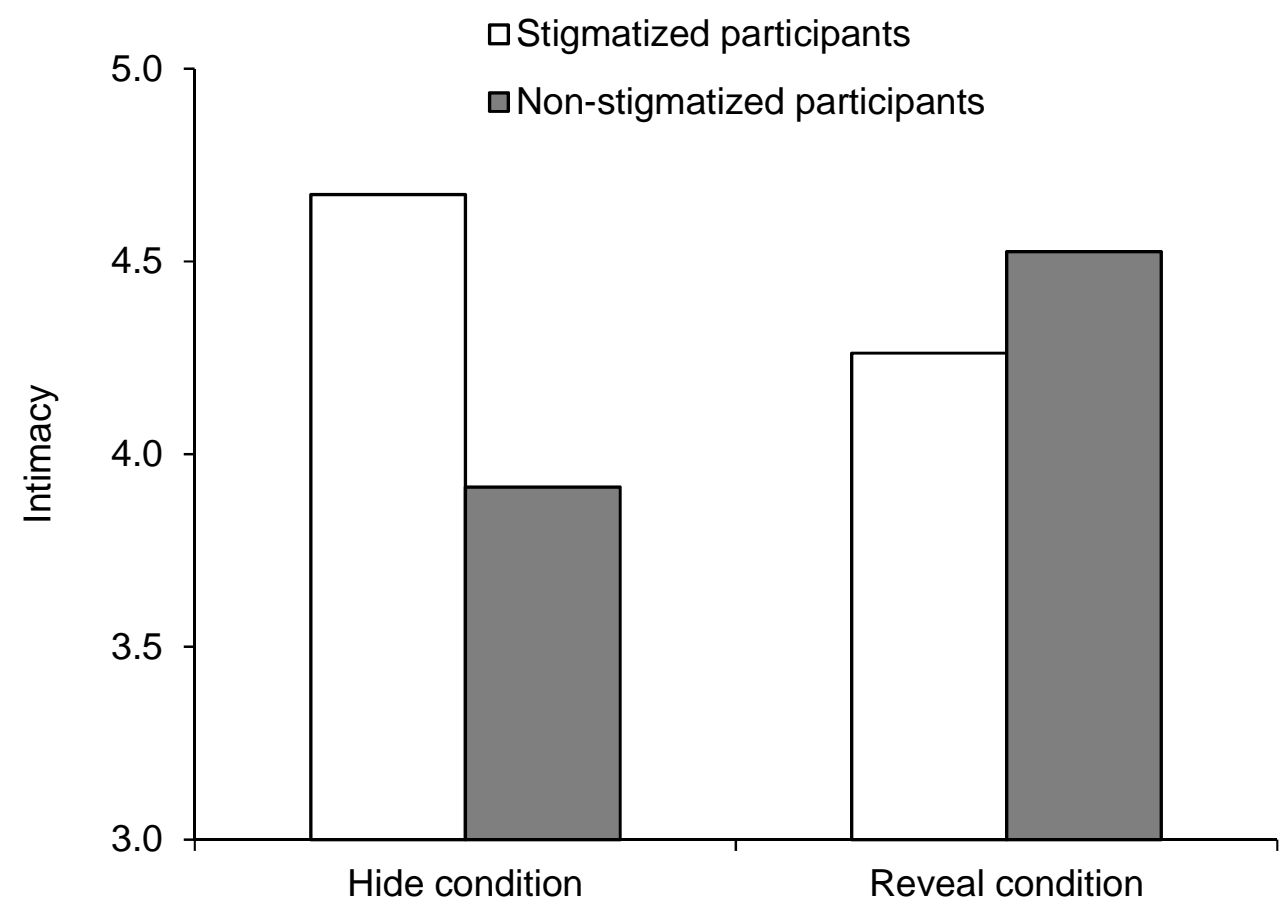

Figure 3. The effect of stigmatized participants' hiding versus revealing their history of mental illness on stigmatized and non-stigmatized participants' feelings of intimacy during the interaction, adjusting for both participants' negative expectations prior to and authenticity during the interaction (Study 3). Scale range: 1-7; higher scores indicate more intimacy. 